\title{
Convergent Validity Study of the Engineering Graphics Concept Inventory
}

\section{Dr. Steven Nozaki, Penn State Erie, The Behrend College}

Ph.D. Engineering Education - The Ohio State University

\section{Dr. Nancy E. Study, Penn State Erie, The Behrend College}

Dr. Nancy E. Study is on the faculty of the School of Engineering at Penn State Behrend where she teaches courses in engineering graphics and rapid prototyping, and is the coordinator of the rapid prototyping lab. Her research interests include visualization, standardization of CAD practices, and haptics. Nancy is a former chair of the ASEE Engineering Design Graphics Division and is currently the Editor and Treasurer of the Engineering Design Graphics Journal. She received her B.S. from Missouri State University, and M.S. and Ph.D. from Purdue University. 


\section{Convergent Validity Study of the Engineering Graphics Concept Inventory}

\section{Introduction}

This paper is a work in progress describing the ongoing assessment of the validity of the Engineering Graphics Concept Inventory. The Engineering Graphics Concept Inventory (EGCI) was the first instrument developed with the intent of measuring understanding and misconceptions in the area of engineering graphics. As technology and methods continue to change, so too will the content and format of the EGCI. Monitoring the EGCI's performance against current trends and practices in engineering graphics can help keep the instrument a useful tool in engineering education research. With the instrument having met its intended level of rigor [1], widespread testing can now be done on different psychometric aspects to better prepare it for widespread use. One of the first measures to be further substantiated is the instrument's validity.

\section{Background}

The EGCI was developed as part of a larger project examining understanding and misconceptions in engineering graphics with a goal of creating an assessment instrument. Experts in the field were consulted to identify important topics in the field which included; Mapping 2D to 3D, Planar Geometry and Projection Theory, and Graphics Conventions [1]. Representative items of each topic were generated. Several iterations of testing refined the items for content, format, and psychometric characteristics. Content was reviewed closely in order to assure that the items accurately represented the identified topics as verified by experts. Format was assessed and improved in two areas; the first was to make sure that items adhered to accepted graphics conventions, and the second was to have the instrument be presented in accordance with accepted practices for instrument development. The primary psychometric values examined were item difficulty and item discrimination. Difficulty is a measure of what percentage of students get an item correct. Discrimination shows how well an item discriminates between high and low performing students on the instrument [2]. Items selected to be on the instrument had a range of difficulties and all were of adequate discrimination. Currently, the instrument has 30 items evenly distributed across the three identified topics [1].

Considering the classical test theory (CTT) model for instrument development, there are three principle types of validity used to evaluate an instrument: criterion, construct, and content [1]. Plainly put, construct validity is the measurement of how much an instrument is measuring the variable it claims to be measuring [4], and the construct validity for this instrument has already been established. Convergent validity, on the other hand, speaks to how correlated two instruments are that claim to measure the same latent ability [1], [6] and it is the convergent validity of the instrument that is being measured in this study. It stands to reason that this new instrument would correlate positively with an established method of measurement. It should also 
be evident that the new instrument correlates well with measures of similar constructs and does not correlate with those that are not [7].

\section{Methods}

Currently the EGCI instrument is housed online on a platform that is institutionally proprietary. To ensure its sustainability for future use and improvement, it is undergoing a conversion to a non-proprietary platform. The conversion is scheduled to be completed during the spring 2019 semester, and the instrument will be used to gather participant data from multiple classes during that semester. A link to access the instrument will be posted in the course management system and after obtaining consent from the participants, the instrument will display a sample item, similar to the one in Figure 1, to familiarize participants with the format. The consent and instructional phase will not be timed. Once beginning the instrument, participants will have 30 minutes to respond to 30 multiple-choice format items. Each item will have 4 responses, 1 correct answer and 3 distractors. The instrument is set up to have the responses for each item appear in random order; e.g. for item 1, the correct response could show up as "A", "B", "C", or "D" for any particular student. Items on the instrument are arranged by three identified constructs, and appear in order of increasing difficulty. The constructs included in the test are Mapping 2D to 3D, Planar Geometry and Projection Theory, and Graphics Conventions.



Figure 1 Sample Item from Instrument

Participants will be given a score of how many correct responses they provided, and will not be penalized for incorrect responses or blank items. A total score out of 30 will be given to the student, along with sub-scores to explain performance on individual constructs [4]. Participants in this study will be students enrolled in one of two introductory engineering graphics courses that are part of a two course sequence over two 15 week semesters. Students are typically enrolled in engineering or engineering technology majors, and are required to take the courses as part of their curriculum.

Both courses contain lab assignments throughout the semester and final projects that are used to assess practical engineering graphics skills, along with written exams and comprehensive final exams that assess theoretical content. Course content includes all the identified constructs addressed in the EGCI. All sections of the same course have the same assignments, grading rubrics, lab practicals, and exams. Performance in the engineering graphics courses will be used as the comparative measure that the EGCI will be evaluated against. An instrument of reasonable convergent validity would show a positive relationship with student performance in classes that 
focus on a similar subject. For this study, performance in class will consider overall course grades, lab activity grades, and exam grades. Further separation of lab activities and exam grades will address the differing applications of knowledge and abilities based on which construct or constructs the assignment or exam addresses. Since there is the potential for variability in the grading of individual instructors, before assessing correlation, grades will be checked for normality of distribution and variance between the course sections. Students will be identified through class (first or second graphics course) and publicly available directory information. Pending institutional research board approval will allow for additional demographic information to be included for analysis.

\section{Discussion}

This first stage of studying convergent validity is being conducted at a single institution. This initial phase serves as a trial for the new platform of the EGCI and initial convergent validity study. It will also function as a trial for large scale implementation of standalone data gathering for the researchers. Successful data collection by the researchers will provide proof of concept for the creation, distribution, and utilization of other STEM assessments. Confirmation that the instrument displays adequate positive correlation with course performance will serve as an indicator that the instrument can continue to be refined and improved in other settings. Failure to meet such standards will provide discouraging, though equally valuable information, particularly in the case of negative correlation. A significant negative correlation might indicate a misalignment of constructs on the instrument and course content. For example, if the instrument were to positively correlate well in another setting, it may indicate poor alignment of course content. It will be up to the researchers to interpret the data and ensure that the data being selected to compare against the instrument is an accurate representation of student performance.

An extension of examining convergent validity would be to compare the results to constructs that should not be associated with the construct being measured. The EGCI aims to measure understanding in engineering graphics concepts; thus, unrelated constructs that should not be associated with an EGCI construct should not have a significant correlation with performance on the instrument. For examples, high performance on the EGCI should correlate with performance in solid modeling courses or other courses requiring an understanding of engineering graphics concepts such as machine design or production design, that require the creation or reading of technical drawings, but perhaps not with performance in history or philosophy classes for the same participants. 


\section{Works Cited}

[1] Sadowski, M., \& Sorby, S. (2014). (2014). Defining concepts for an engineering concept inventory: A Delphi study. Paper presented at the Proceedings of the 69th Midyear Meeting of the Engineering Design Graphics Division of ASEE, Normal IL. 67-72.

[2] Study, N.; Nozaki, S., Sorby, S., Sadowski, M.; Steinhauer, H.,; Miller, R; Nabutola, K. "Creating a Concept Inventory - Lessons Learned", in ASEE Annual Conference and Exposition. Salt Lake City, Utah, 2018.

[3] Nozaki, S., Sorby, S., Steinhauer, H., Study, N., Sadowski, M., \& Miller, R. (2016). (2016). The development of a concept inventory for engineering graphics. Paper presented at the ASEE Annual Conference Proceedings, New Orleans, Louisiana.

[4] Bechger, T. M., Maris, G., Verstralen, Huub H. F. M., \& Béguin, A. A. (2003). Using classical test theory in combination with item response theory. Applied Psychological Measurement, 27(5), 319-334.

[5] Engelhardt, P. V. (2009). An introduction to classical test theory as applied to conceptual multiple-choice tests. In C. Henderson, \& K. A. Harper (Eds.), Getting started in PER (). College Park, MD: American Association of Physics Teachers. Retrieved from http://www.per-central.org/items/detail.cfm? ID $=8807$

[6] Crocker, L. M., \& Algina, J. (1986). Introduction to classical and modern test theory. New York: Holt, Rinehart, and Winston

[7] Brennan, R. L. (2011). Generalizability theory and classical test theory. Applied Measurement in Education, 24(1), 1-21

[8] Gay, L. R., Mills, G. E., \& Airasian, P. W. (2006). Educational research: Competencies for analysis and applications. Upper Saddle River, N.J.: Pearson Merrill Prentice Hall

[9] S. Y. Nozaki, "The Development of a Concept Inventory for Engineering Graphics." , ProQuest Dissertations Publishing, 2017. 